\title{
De la televisión a la televisión extendida a partir de Marshall Mcluhan
}

\author{
From the television to the extended television after Marshall Mcluhan
}

Octavio Islas Carmona ${ }^{1}$

\begin{abstract}
RESUMEN
Este texto comprende cuatro apartados. En el primero, recuperé el emotivo discurso que dictó Wilbur Schramm sobre el desarrollo de la primera transmisión de televisión, realizada el 26 de enero de 1926 por John Logie Baird, para fundamentar la pertinencia del término "Edad de la televisión". La televisión admite ser considerada como el medio emblemático de la "Edad Eléctrica". En el segundo apartado analicé las tesis que Marshall McLuhan desarrolló sobre el llamado "gigante tímido". A comienzos de la década de 1960, la televisión cautivaba a Marshall McLuhan. Desde una particular perspectiva ecuménica, el canadiense creía que la televisión restablecería el equilibrio sensitivo, propiciando el tránsito a la "aldea global". Con el paso de los años, el optimismo que profesaba por la televisión fue desvaneciéndose, $y$ en sus últimos libros McLuhan adoptó una posición definitivamente crítica frente a esta, similar a la profesada por Neil Postman. En el tercer apartado, destaque que McLuhan anticipó la convergencia mediática, procedí a explicar su Tétrada, y referir como Bob Logan (2010) la empleó para analizar la televisión y la televisión por cable. Por último, en el cuarto apartado, recuperé la Tétrada de los McLuhan para analizar algunas de las modalidades más interesantes de la televisión extendida: Youtube, Netflix e Internet Protocol Television (IPTV)- en castellano: televisión a través de protocolo de Internet.
\end{abstract}

\section{Palabras clave}

Marshall McLuhan, televisión, Ecología de los medios, televisión extendida.

\begin{abstract}
This text is composed of 4 sections. In the first one, I recovered the emotive speech made by Wilbur Schramm about the first television broadcasting carried out on January 26th 1926 by John Logie Baird in order to support the relevance of the term "Age of television". The television is actually considered as the emblematic media in the "Age of electricity". In the second section, I studied the thesis developed by Marshall McLuhan about the so-called "shy giant". At the beginning of 1960s, the television captivated Marshall McLuhan. From a particular ecumenical perspective, the Canadian researcher believed that the television would restore the sensitive balance, thus favoring the transition to the "global village". As the years went by, his optimism about the television started to vanish, and McLuhan adopted a more critical position, similar to Neil Postman's, against the television. In the third section, I stood out that McLuhan anticipated the media convergence; then, I explained his Tetrada and pointed out the way Bob Logan (2010) used it to make an analysis of the television and the cable television. Finally, in the fourth section, I recovered the Tetrada from McLuhan to study some of the most interesting modalities of extended television: Youtube, Netflix and Internet Protocol Television (IPTV).
\end{abstract}

\section{Keywords}

Marshall McLuhan, television, Media ecology, extended televisión.

\footnotetext{
Doctor en ciencias sociales. Director del Centro de Altos Estudios en Internet y Sociedad de la Información, en la Universidad de los Hemisferios, Quito, Ecuador. Director y fundador de la revista web Razón y Palabra, primera publicación especializada en temas de comunicología en el ciberespacio iberoamericano [http://www.razonypalabra.org.mx]. Autor y coordinador de 14 libros. Miembro de la Media Ecology Association (MEA). Director de investigación del World Internet Project Ecuador (WIP-Ecuador).
} 


\section{La Edad de la Televisión}

"Sería fácil elaborar un manual completo para el estudio de las extensiones del hombre con pasajes escogidos de las obras de Shakespeare. Muchos se pondrán a sutilizar si se refería o no a la televisión en estas conocidas líneas de Romeo y Julieta:

Pero suave, ique luz trasluce de aquella ventana?

Habla, y sin embargo no dice nada". Marshall McLuhan.

En las memorias del "Segundo Encuentro Mundial de la Comunicación. La edad de la Televisión", acto organizado por Televisa, en julio de 1979, en Acapulco, Guerrero, Wilbur Lang Schramm (1907-1987), reconocido sociólogo estadounidense e investigador de los medios masivos de comunicación - con quien no precisamente simpatizaba Marshall McLuhan-, ofreció un emotivo discurso sobre el desarrollo de la primera transmisión de televisión, realizada el 26 de enero de 1926 por John Logie Baird (1988-1946), ingeniero y físico escocés, inventor del primer sistema de televisión mecánica, así como del primer tubo de televisión en color:

Vamos a hablar de la Edad de la Televisión (...) En 1904, en Inglaterra, un ingeniero llamado Midford hizo un diseño de televisión que hubiera funcionado si hubieran podido fabricar los tubos. Luego vinieron Farnsworth y Lee De Forest (...) Sucedió en Inglaterra, un martes 26 de enero de 1926. Los principales invitados pertenecían a la "Royal Society": los grandes hombres de ciencia del país. Voy a leerles lo que ocurrió aquella noche: Era una fría noche de enero y los miembros de la Institución Real llegaron por parejas o de tres en tres. Al salir de la demostración, sus observaciones, por lo que pude oír, eran del tenor esperado. Algunos decían no era nada digno de consideración, otros pensaban que era algo que un joven hacía aunque realmente no sabía a ciencia cierta qué estaba haciendo. Solo unos pocos pensaron que podía ser algo interesante, a nadie se le ocurrió que este pudiera ser el nacimiento de un nuevo medio, algo que tendría más efecto en nuestra vida que ninguna otra cosa desde la invención del automóvil" Y seguía diciendo: "La imagen recibida era burda pero reconocible, como un rostro o un florero con flores, un librero abierto o cerrado o cualquier otra cosa simple de uso diario. La imagen recibida era de color rosado y tendía a oscilar de arriba abajo. No era posible ver gran cosa del aparato que estaba cubierto". Al día siguiente el periódico The London Times publicó esta reseña: "Era un gran disco giratorio de madera que contenía lentes tras los cuales había un obturador giratorio y una celda fotosensible. La cabeza de un muñeco de ventrílocuo era manipulada como imagen que se transmitía, aunque también se reproducía un rostro humano, primero, en un receptor en la misma habitación que el transmisor, y luego, en un receptor portátil en otra habitación. Se mostró a los visitantes una recepción reconocible de los movimientos del muñeco y de la persona que hablada y la imagen, en la transmisión, era débil y a menudo borrosa pero aún así, confirmó que el televisor, como lo llama el Sr. Baird, puede transmitir y reproducir instantáneamente los detalles de movimiento y cosas tales como las distintas expresiones de un rostro (Televisa, 1979, p. 14).

Ese fue el modesto inicio de la televisión -un gigante tímido-, como atinadamente le llamó Marshall McLuhan (1911-1980).

En el libro Understanding Media: ${ }^{2}$ The extensions of man (1964) —en castellano: Comprender los medios de comunicación. Las extensiones del hombre-, cuarto libro

\footnotetext{
2 Conviene tener muy presente la diferencia que McLuhan estableció entre medium y media, la cual resulta fundamental en la comprensión de UM, como en la obra de McLuhan. Media remite a los medios de comunicación. Medium es cualquier extensión de nosotros, toda nueva tecnología.
} 
de Herbert Marshall McLuhan, el capítulo XXXI fue dedicado a la televisión, el media emblemático de la "Edad Eléctrica". En UM como en posteriores libros, por ejemplo, The medium is the massage (1967) -en castellano: El medio es el masaje-, McLuhan anticipó el tránsito a una nueva etapa histórica, una edad post eléctrica que designó como Information Age -en castellano: Edad de la información-. El concepto "Edad de la Información", originalmente concebido por McLuhan, fue recuperado por Daniel Bell (1919-2011) en el libro El advenimiento de la sociedad posindustrial (1973). También Alvin Toffler (n. 1928) especuló sobre la Edad de la Información en el libro La Tercera Ola (1979).

La Edad eléctrica dio inicio con la invención del telégrafo. El telégrafo incrementó significativamente la velocidad con la cual circulaba la información - por primera vez en la historia, el mensaje antecedió la llegada del mensajero-. En principio, el desarrollo del telégrafo estuvo subordinado al periódico y al ferrocarril. Los vínculos entre las comunicaciones y los sistemas de transporte entonces eran evidentes. En 1844, Samuel Morse abrió una línea telegráfica entre Washington y Baltimore. En 1858, ya se había tendido el primer cable que cruzaba el Atlántico, y tres años después, en 1861, los hilos telegráficos se extendieron por toda la Unión Americana. Gracias al telégrafo, el hombre, por primera vez, logró prolongar su sistema nervioso central fuera de sí. El telégrafo nos instaló - afirmó McLuhan- ante los umbrales de la Edad de la Información:

Es la misma provisión de lugares de interacción en los medios eléctricos la que nos fuerza a reaccionar al mundo como un todo. No obstante, es sobre todo la velocidad de la implicación eléctrica la que crea el conjunto integral de la conciencia individual y pública. Hoy en día vivimos en la Edad de la Información y de la Comunicación, porque los medios eléctricos crean, instantánea y constantemente, un campo total de acontecimientos en interacción, en los que participan todos los hombres. (McLuhan, 1996, p. 257).
La velocidad instantánea del movimiento de información, precisamente partió del telégrafo:

[el telégrafo] revolucionó por completo los métodos de obtención y presentación de las noticias (...) Así, en 1844, año en el que se jugaba al ajedrez y a la lotería con el primer telégrafo estadounidense, Soren Kierkergaard publicó El concepto de la angustia. Había empezado la edad de la ansiedad. Con el telégrafo, el hombre había iniciado aquella extensión o exteriorización del sistema nervioso central que ahora se acerca a la extensión de la conciencia (McLuhan. 1996, p. 260).

Es posible afirmar que la Edad de la Electricidad -inaugurada por el telégrafo- fue también la "Edad de la Televisión" - como señaló Wilbur Schramm-. En la siguiente etapa — La Edad de la Información-, esta circula aún más rápido que en la Edad eléctrica, y en buena medida ello ha sido posible por Internet, complejo media con el cual se ha alcanzado la instantaneidad informativa.

\section{El "gigante tímido"}

A partir de un artículo de Edith Efron, Marshall McLuhan designó a la televisión como "gigante tímido". En Understanding Media, McLuhan ofreció la siguiente explicación sobre el sentido de tal metáfora: "Un artículo de Edith Efron en TV Guide (18-24 de mayo de 1963) calificaba a la televisión de "gigante tímido" porque no es adecuado para los temas calientes ni para las controversias nítidamente definidas" (McLuhan, 1996: p. 316).

Debemos tener presente que en el segundo capítulo de Understanding Media - "Media calientes y fríos"-, McLuhan introdujo una interesante taxonomía, derivada de la termodinámica, para clasificar a los media en fríos o calientes (Steam, 1967). Los media fríos son de baja definición y demandan la participación de los usuarios para complementar la información que ofrecen. Los media calientes son de alta definición y no necesitan de la participación de los usuarios para complementar la información que 
ofrecen. Los media fríos incluyen mientras que los media calientes excluyen.

Hay un principio básico que distingue un medio caliente como la radio, de otro frío como el teléfono; o un medio caliente como la película de cine de otro frío como la televisión. El medio caliente es aquel que extiende, en "alta definición", un único sentido. La alta definición es una manera de ser, rebosante de información. Una fotografía es, visualmente, de alta definición. La historieta es de "baja definición" simplemente porque aporta muy poca información visual. El teléfono es un medio frío, o de baja definición, porque el oído sólo recibe una pequeña cantidad de información. El habla es un medio de baja definición por lo poco que da y por lo mucho que debe completar el oyente. Un medio caliente, en cambio, no deja que su público lo complete tanto (McLuhan, 1996, p. 43).

McLuhan incluyó a la televisión en el repertorio de media fríos, de baja definición, y que, en consecuencia, deben ser complementados por la audiencia. Las culturas frías o con un bajo nivel de alfabetización -McLuhan extendió su tesis sobre los medios fríos y calientes al análisis de las sociedades, las culturas, y también de personajes de la política- no pueden tomar como espectáculos los media calientes del cine o de la radio. Su media idóneo es la televisión. En la Edad de la Televisión somos fríos (McLuhan, 1996, p. 47). Como media frío:

la televisión ha introducido, en opinión de algunos, una especie de rigor mortis en el público como ente político. La incapacidad del medio televisivo para abordar los temas calientes se debe a su extraordinario grado de participación de la audiencia (...) Las cadenas se alegran si levantas una polémica en un país a veinte mil kilómetros de aquí: No quieren controversia, ni verdadera disidencia en casa. El comportamiento de la televisión resulta incomprensible a la gente condicionada en el medio caliente del periódico, que se centra en el choque de opiniones en vez de la implicación en profundidad de la situación (McLuhan, 1996, p. 316).

Por ser un media frío, la televisión rechaza las personalidades muy definidas. Además, la televisión - visualmente pobre en datos- no funciona como fondo, termina por implicarnos. La televisión "tiende a ser un medio de primer plano". De acuerdo con McLuhan, el éxito de cualquier artista de la televisión depende de conseguir un estilo de presentación de baja presión. La imagen de la televisión: "es de baja intensidad o definición y, por lo tanto, a diferencia del cine, no puede permitirse una información detallada de los objetos" (McLuhan, 1996, p. 323). Con respecto a los contenidos de los programas de televisión, McLuhan señaló: "Como la baja definición de la televisión asegura un elevado grado de implicación de la audiencia, los programas más efectivos son los que presentan situaciones que consisten en algún proceso que se ha de completar (...) La televisión no es tanto un medio de acción como de reacción" (McLuhan, 1996, p. 325).

En cuanto a las principales diferencias entre la radio - media caliente-, y la televisión media frío-, McLuhan destacó:

La televisión es un medio frío y participativo. Cuando se lo calienta con dramatizaciones y añadidos, no funciona tan bien porque hay menos oportunidades de participación. La radio es un medio caliente. Cuando se lo carga con una intensidad adicional, funciona mejor. La radio puede servir de fondo o de control de ruidos, como cuando el ingenioso adolescente lo utiliza para rodearse de intimidad. La televisión no funciona de fondo. Lo implica a uno. Hay que estar en ello. (McLuhan, 1996: p. 318).

Por supuesto, no han faltado críticos de McLuhan que han afirmado que la taxonomía que concibió para clasificar los media en fríos y calientes, en realidad fue una más de sus ocurrencias. Sin embargo, Federman y de Kerckhove (2003), en el libro McLuhan for Managers -en castellano: McLuhan para administradores-, particularmente en el 
capítulo "Business. Hot and cool"-Negocios. Caliente y frío-, recuperaron la tesis de Marshall McLuhan sobre media fríos y calientes, adecuándola a los propósitos del referido libro para emprender el análisis de las relaciones entre directivos, instituciones y el clima laboral resultante. En el citado capítulo Federman $y$ de Kerckhove precisamente abordaron la evolución de la televisión, señalando que, a partir del advenimiento de la televisión digital, ese media frío empezó a ser transformado en un media caliente, confirmando así la evolución de los media -tesis designada como "remediación" por algunos destacados teóricos en la Media Ecology -en castellano: Ecología de los Medios-, particularmente Jay Bolter y Richard Grusin (1999).

Sin embargo, debemos tener presente que para Marshall McLuhan, la baja definición de la televisión no solo representaba un atributo técnico; además, la consideraba como una condicionante de las posibilidades del discurso de la televisión:

Con la televisión, el telespectador es la pantalla (...) La imagen de televisión es visualmente pobre en datos. La imagen televisiva no es un plano fijo. De ningún modo es fotografía, sino una ininterrumpida formación de los contornos de las cosas, trazados por barrido. El contorno plástico resultante aparece en virtud de una luz que lo atraviesa en lugar de iluminarlo, y la imagen así formada tiene calidad, no tanto pictórica, sino de ícono y de escritura". La imagen televisiva ofrece al telespectador unos tres millones de puntos por segundo. De estos, solo acepta unas cuantas docenas para elaborar la imagen. La imagen de cine ofrece muchísimos más millones de datos por segundo y el espectador no tiene que efectuar la misma reducción drástica de elementos para formarse una impresión. En vez de ello, tiende a aceptar la imagen como un paquete (McLuhan, 1996, p. 318).
Aun cuando McLuhan objetó la posibilidad de que la televisión pudiera ser transformada en un media caliente, anticipó la evolución de los media -tesis que hoy resulta central en el desarrollo de la teoría de las remediaciones-. Los media cambian gracias a la intervención del hombre: "Estos medios, por ser extensiones de nosotros, también dependen de nosotros por sus interacciones y su evolución" (McLuhan, 1998, p. 70).

Frente a la cámara de cine, la cámara de televisión presentaba importantes limitaciones. La cámara de televisión - afirmó McLuhan"carece del ángulo de visión incorporado que tiene la de cine". McLuhan inclusive se planteó la posibilidad de que la definición de la imagen televisiva efectivamente pudiera llegar a ser similar a la imagen cinematográfica, concluyendo, sin embargo, que la televisión 'mejorada' ya no sería televisión.

De acuerdo con McLuhan, todas las tecnologías $-\mathrm{y}$ los medios de comunicación son tecnologías-, admiten ser consideradas como prolongaciones de los sentidos, miembros o facultades del ser humano. Cualquier extensión afecta todo el sistema psíquico o social. Todas las extensiones responden a una situación compleja: la necesidad de mantener el equilibrio en un mundo inevitablemente caótico. ${ }^{3}$ Cuando Marshall McLuhan escribió su cuarto libro (1964), parecía cautivado por la televisión. Sin embargo, con el paso de los años paulatinamente se desilusionaría de esta. Al convertirse al catolicismo, McLuhan asumió la vida de un verdadero devoto. En sus últimos años de vida - afirman sus biógrafos-asistía a misa y comulgaba todos los días. Desde su particular visión ecuménica, explicitada por Eric McLuhan y Jacek Szkiarek en el libro The medium and the light. Reflections on religion, (1999), McLuhan creía que la televisión posibilitaría el tránsito a la "aldea global", que devolvería al hombre el equilibrio sensorial que perdió con el advenimiento del alfabeto. Por ello en el libro Comprender los

Ello precisamente permite afirmar los estrechos vínculos que admite la Media Ecology -en castellano: Ecología de los Medios- con la complejidad (Morin, Luhman). 
medios de comunicación: Las extensiones del ser humano, Marshall McLuhan consideró a la televisión como extensión del sentido del tacto, y no del sentido de la vista, como parecía lógico suponer (McLuhan, 1996, pág. 338). El tacto implica la interacción de todos los sentidos. Además sostenía que la imagen televisual invertía el proceso alfabético de fragmentación analítica de la vida sensorial.

En la década de 1960, la televisión resintió importantes cambios tecnológicos. $\mathrm{La}$ introducción de sistemas VCR, por ejemplo, modificó radicalmente los esquemas de producción televisiva. Los nuevos formatos favorecieron el desarrollo de nuevas audiencias. Entonces fue necesario producir televisores capaces de soportar un mayor número de horas en operación, pues los primeros televisores de bulbo frecuentemente se sobrecalentaban y las reparaciones resultaban muy costosas. Con la introducción de las primeras transmisiones en color, el televisor fue elevado a la condición de símbolo del estatus y el poder adquisitivo de numerosas familias de clase media, quienes orgullosamente ubicaron al televisor en un sitio privilegiado en la sala de sus hogares. La televisión, además, consiguió trascender su alcance, básicamente regional, mediante la introducción de sistemas por cable $y$, posteriormente, a través de enlaces satelitales. El desarrollo de la industria satelital remedió tanto a la televisión como a la telefonía. Las remediaciones que ha resentido la televisión a través de su historia han sido numerosas, por ejemplo, el control remoto, la televisión digital, la televisión de alta definición (HDTV), la Web TV, You Tube, televisión a través de celulares, digital video recorders (DVT), TiVo, ReplayTV, YouTube, Netflix, Internet Protocol Television (IPTV), etc.

Una de las causas de ruptura más comunes en cualquier sistema "es la fertilización cruzada con otro sistema" (McLuhan, 1996, p. 59). En los años recientes, las remediaciones más importantes que ha resentido la televisión proceden de Internet. Además, debemos tener presente que las audiencias han cambiado. Hoy los públicos desean proponer sus propios contenidos, y para ello aprovechan YouTube o plataformas similares:
En palabras de Betsy Frank, vicepresidenta ejecutiva de investigación y planificación de MTV Networks, "se trata de un público que desea hacer su propia programación". Los nuevos instrumentos del consumidor ya otorgan a los teleespectadores el poder de cortar y pegar partes de programas para adecuarlos a sus preferencias personales. Este desplazamiento continuo de los tiempos estándar de los huecos en la programación se acelerará a medida que las audiencias de los medios de comunicación, provistas de nuevas tecnologías, produzcan sus propios contenidos. Al mismo tiempo que los espectadores están creando sus propios contenidos, también exigen acceder a programas "a petición" antes que al horario establecido por los medios de comunicación. En palabras de William Randolph Hearst III, "la televisión basada en el proveedor está muerta (Toffler, 2006, p. 99).

Sin duda alguna, el futuro de la televisión dependerá de la interactividad.

\section{3.- Televisión, convergencia y la Tétrada de McLuhan}

En el segundo capítulo de Understanding Media, McLuhan anticipó el concepto de "convergencia mediática", designándolo bajo el término "concentricidad", y señalando que la concentricidad, con su infinita concepción de planos, es necesaria para la comprensión intuitiva, ya que ningún medio tiene sentido por sí mismo, solamente en interacción constante con otros medios. Como atinadamente sostiene Henry Jenkins (n. 1958), la convergencia representa un cambio en nuestros modos de pensar nuestras relaciones con los medios. La convergencia comprende el flujo de contenido a través de múltiples plataformas mediáticas, cooperación entre múltiples industrias mediáticas, el comportamiento migratorio de las audiencias mediáticas; dispuestas a ir a cualquier parte en busca del tipo deseado de experiencias y entretenimiento.

En Understanding Media, McLuhan advirtió que las hibridaciones —como las narrativas transmediáticas-, son procesos indispensables 
de renovación que nos liberan de la narcosis o el entumecimiento que pueden propiciar los media:

La hibridación o encuentro de dos medios es un momento de la verdad y de la revelación del que surgen nuevas formas. El paralelismo entre dos medios nos mantiene en las fronteras de formas que nos despiertan de la Narciso-narcosis. El encuentro de varios medios es un momento de libertad y de liberación del trance ordinario $y$ del entumecimiento que imponen a los sentidos (McLuhan, 1996, p. 76).

McLuhan desarrolló una rigurosa metodología para el estudio de los media y los medium en el libro Laws of Media. The new science -en castellano: Las leyes de los medios. La nueva ciencia- ${ }^{4}$ cuya primera edición fue publicada en 1988.

Marshall McLuhan falleció el 31 de diciembre de 1980. Este libro -que de acuerdo con Eric McLuhan, admite ser considerado como la perfecta continuación de Understanding Media-, fue concluido por Eric, el mayor de los hijos de Marshall. Sobre los antecedentes del referido libro, cabe señalar que McLuhan primero publicó dos pequeños artículos sobre el tema, y en sus últimos años de vida continuó trabajando en ese proyecto con Eric y con otros investigadores.

En Laws of Media, los McLuhan introdujeron cuatro leyes que admiten ser aplicadas, sin excepción, a todas las creaciones del hombre, tangibles como intangibles, abstractas o concretas. Las cuatro leyes permitieron confirmar que las tecnologías y los medios pueden prolongar las funciones humanas. Las tecnologías mecánicas sirven para extender nuestro cuerpo físico, mientras que los medios de comunicación extienden nuestra psique o el sistema nervioso. Para definir las cuatro leyes de los medios, los McLuhan partieron de las siguientes preguntas: ¿Qué afirmaciones podemos hacer acerca de los medios de información que cualquiera pueda poner a prueba - confirmar o refutar-?; ¿qué tienen en común todos los medios informativos? $\mathrm{Si}$ formulamos las preguntas que soportan las cuatro leyes, estas serían: ¿Qué extienden los medios o tecnologías?, ¿Qué vuelven obsoleto?, ¿Qué recuperan?, ¿Qué revierten? La representación gráfica de las citadas interrogantes es conocida como la tétrada de McLuhan, que no debe ser considerada secuencialmente. En realidad, se trata de cuatro procesos más o menos simultáneos.

La primera ley, relativa a la extensión, indica que toda tecnología extiende una facultad física o psíquica del hombre - debemos tener presente que el concepto de extensión supone la posibilidad de prolongar, reemplazar, incrementar, reforzar, acelerar, intensificar-. Cada medio, tecnología o artefacto hecho por el hombre mejora alguna función humana.

La segunda ley, que corresponde a la obsolescencia y es consecuencia directa de la extensión, implica que cuando un medio prolonga una facultad física o psíquica, determinadas partes del entorno de lo extendido se vuelven obsoletas. Las tecnologías extienden, pero también amputan. La amputación es inevitable. Mientras determinados sentidos o facultades se incrementan, otros inevitablemente disminuyen. Toda nueva tecnología vuelve obsoletas tecnologías precedentes. McLuhan comprendía la obsolescencia, no como el final sino el comienzo de algo nuevo.

El concepto medular de la tercera ley es la recuperación. La estructura social resiente los efectos de toda nueva tecnología y paulatinamente recupera su equilibrio. En ocasiones, la recuperación es resultado de adaptaciones o procesos compensatorios.

La cuarta ley se define a partir de la reversión. Cuando la tecnología llega a su límite, que en términos mcluhianos significa el sobrecalentamiento del medio-, suelen

4 Vale la pena consultar un interesante sitio web que centra su atención sobre Las leyes de los medios. La nueva ciencia: http://www.lawsofmedia.com/bibliography.html Quizá el primer antecedente inmediato de las leyes de los medios sea el texto "Laws of the Media", publicado en la revista Et Cetera 34 (2): 173-79. 
presentarse hechos y situaciones que revierten o "enfrían" la tendencia. Un medio solo revierte porque se ha llevado al límite.

Robert Logan (n. 1939), destacado discípulo de McLuhan y miembro de la segunda generación de la Escuela de Toronto - a pesar de su origen neoyorquino-, recuperó la Tétrada de los McLuhan para analizar varios media, entre ellos, la televisión, en el libro Understanding new media: Extending Marshall McLuhan (2010):

Figura 1. Televisión

\begin{tabular}{|c|c|l|l|}
\hline \multicolumn{1}{|c|}{ Extiende } & \multicolumn{1}{|c|}{ Revierte } & \multicolumn{1}{c|}{ Recupera } & \multicolumn{1}{c|}{ Caduca-disminuye } \\
\hline $\begin{array}{l}\text { Mosaico de imágenes a } \\
\text { distancia. }\end{array}$ & Somnolencia. & $\begin{array}{l}\text { Recupera el } \\
\text { espectáculo. }\end{array}$ & $\begin{array}{l}\text { Hace obsoleta a la radio y el } \\
\text { cine. }\end{array}$ \\
\hline
\end{tabular}

Fuente: Logan. 2010

De la televisión por cable, Logan dedujo la siguiente tétrada:

Figura 2. Televisión por cable

\begin{tabular}{|l|l|l|l|}
\hline \multicolumn{1}{|c|}{ Extiende } & \multicolumn{1}{c|}{ Revierte } & \multicolumn{1}{c|}{ Recupera } & Caduca-disminuye \\
\hline $\begin{array}{l}\text { Amplifica la calidad } \\
\text { y diversidad de la } \\
\text { recepción de la señal. }\end{array}$ & $\begin{array}{l}\text { Vuelta a la } \\
\text { radiodifusión en casa. }\end{array}$ & $\begin{array}{l}\text { Recupera patrón } \\
\text { de difusión punto a } \\
\text { punto. }\end{array}$ & $\begin{array}{l}\text { Hace obsoleta la } \\
\text { radiodifusión. }\end{array}$ \\
\hline
\end{tabular}

Fuente: Logan. 2010

En el siguiente apartado, con base en la Tétrada de McLuhan procederé a analizar algunas de las más interesantes modalidades de TV extendida por Internet: YouTube, Netflix y la Internet Protocol Television (IPTV).

\section{4.- La televisión extendida por Internet}

\subsection{YouTube: el parteaguas en los sistemas de distribución de videos}

De acuerdo con lo asentado en Wikipedia, You Tube fue creada en febrero de 2005 por tres ex empleados de PayPal: los ingenieros Chad Hurley (n. 1977), Steve Chen (n. 1978) y Jawed Karim (n. 1979), diseñador alemán. Como ocurrió con algunos de los grandes inventos en la historia, YouTube derivó de una preocupación muy modesta: poder subir a Internet videos que fueron realizados durante una fiesta. Sin embargo, Jawed Karim ha negado tal versión, atribuyéndose la autoría intelectual de YouTube.

El dominio de YouTube fue activado el 15 de febrero de 2005, y el 23 de abril fue incorporado el primer video: "Me at the Zoo" -en castellano: yo en el zoológico Steve Chen-, realizado por Jawed Karim. El tráfico se disparó cuando los usuarios de MySpace empezaron a extender vínculos hacia YouTube, al descubrir que en esa plataforma resultaba muy sencillo poder subir videos. En octubre de 2005, Nike colocó en YouTube un comercial protagonizado por Ronaldinho, el reconocido futbolista brasileño, entonces gran estrella en el club Barcelona. Ello despertó el interés de las grandes firmas de publicidad. Time Warner y Sequoia Capital decidieron invertir en YouTube. En diciembre de 2005, YouTube registraba un promedio de 50 millones de visitas al día. Sin embargo, después de que fue incorporado a YouTube el video musical Lazy Sunday - en castellano: Lunes flojo-, el cual originalmente fue transmitido en la popular serie de la televisión estadounidense Saturday Night Live —en castellano: sábados por la noche en vivo-, el promedio de visitas diarias se disparó a 250 millones por día.

En mayo de 2006, You Tube alcanzó 2,000 millones de visitas diarias. Entonces el New York Post estimó el valor de YouTube entre 600 y 1,000 millones de dólares. Por supuesto, surgieron algunos imitadores. Google y MySpace.com presentaron sus respectivas versiones, sin embargo, estas no tuvieron éxito. En septiembre de ese 
año, Mark Cuban (n. 1958), fundador de Broadcast.com - hoy presidente de la cadena de cable AXS TV (HDTV)_, declaró que "solo un tonto compraría YouTube por los potenciales problemas que generaría". Para colmo, en el mes de octubre un vocero de Universal Music Group declaró que YouTube les debía una millonaria suma de dinero por violaciones a derechos de autor. Sin embargo, una filtración publicada en The Wall Street Journal, calificada entonces por YouTube y Google como simple rumor, anticipó la venta de YouTube a Google por 1,600 millones de dólares - en realidad fue concretada en 1,650 millones de dólares-. Google fue el "tonto" que compró YouTube. Entonces el promedio de videos que diariamente eran incorporados a YouTube ascendía a 65,000 y se estimaba que 100 millones de videos ya habían sido incorporados a la plataforma, la cual registraba un promedio de 72 millones de visitas mensuales. En las oficinas de YouTube, ubicadas en el segundo piso de un edificio ubicado en el condado de San Mateo, entonces laboraban 67 personas. Hurley y Chen siguen laborando en YouTube, hoy propiedad de Alphabet Inc - corporativo derivado de Google-. El lema de YouTube es Broadcast Yourself -transmite tú mismo-.

YouTube admite ser considerado como un parteaguas histórico que ha transformado tanto a los sistemas de producción como de distribución de videos. A través de esta gran videoteca digital, los usuarios de Internet pueden compartir videos, clips de películas, programas de televisión, videos musicales, videoblogs, etc, sin pasar por la burocracia que determina la selección de nuevos contenidos en los canales de televisión, quienes eligen qué videos o producciones son transmitidas $y$ cuáles no.

A pesar de que cuenta con más de mil millones de usuarios, YouTube no precisamente representa un atractivo negocio para Alphabet Inc. La infraestructura es cara y se estima que 40 por ciento de los usuarios de YouTube emplea Adblock para evitar los anuncios. Por ello fue incorporado YouTube Red, servicio que comprende un sistema de pagos por suscripción (10 dólares), y que ofrece videos offline y contenidos originales a los suscriptores, evitándoles la exposición a anuncios.

Figura 3. YouTube

\begin{tabular}{|c|c|c|c|}
\hline Extiende & Revierte & Recupera & Caduca-disminuye \\
\hline $\begin{array}{l}\text { Amplía la diversidad de } \\
\text { la televisión, posibilitando } \\
\text { la exposición de videos } \\
\text { realizados por videoastas } \\
\text { amateurs e independientes. }\end{array}$ & $\begin{array}{l}\text { Litigios en materia } \\
\text { de derechos de } \\
\text { imagen, derechos de } \\
\text { autor y propiedad } \\
\text { intelectual. }\end{array}$ & $\begin{array}{l}\text { Recupera la } \\
\text { producción de } \\
\text { videos caseros. }\end{array}$ & $\begin{array}{l}\text { Hace obsoleta los } \\
\text { sistemas de evaluación } \\
\text { y selección de nuevos } \\
\text { contenidos en canales y } \\
\text { estaciones de televisión. }\end{array}$ \\
\hline
\end{tabular}

Fuente: Elaboración propia

\subsection{Netflix}

De acuerdo con Wikipedia, Netflix Inc. es una firma estadounidense fundada en 1997 por Reed Hastings (n. 1960) y Marc Randolph (n. 1962), con sede en Los Gatos, California, y que originalmente fue concebida como una especie de videoclub. Su principal fortaleza fue ofrecer vía streaming -en castellano: mediaflujo- películas y series de televisión bajo demanda por Internet, y DVD por correo. Los DVD -ahora principalmente Blu-rayson enviados mediante Permit Reply Mail. El servicio de streaming de Netflix funciona con un reproductor basado en Microsoft Silverlight, el cual impide que el contenido audiovisual sea descargado, aunque también cuenta con la opción de usar un reproductor creado con HTML5.

El 25 de febrero de 2007, Netflix entregó el DVD número mil millones. Dos años después, en 2009, la firma ofrecía una colección de 100,000 títulos en DVD y Blu-ray, y había alcanzado 10 millones de suscriptores. En abril de 2011, ya contaba con más de 23 millones de suscriptores en Estados Unidos y 26 millones más en el mundo. Actualmente, tiene más 
de 60 millones de suscriptores en el mundo, y ha producido algunas series exitosas, como House of cards. Además, Netflix ha producido algunas exitosas series para el público latino, como "Narcos", inspirada en la vida de Pablo Escobar Gaviria (1949-1993), famoso narcotraficante colombiano, líder histórico del Cartel de Medellín.
En años recientes, Netflix ha empezado a posicionarse como un servicio de lujo, con ofertas de calidad, dejando atrás la época en la cual pretendió ser reconocido como un enorme catálogo de películas y series estrategia que hoy observa- Hulu, firma que en Estados Unidos compite contra Netflix. Hulu es propiedad de NBC Universal, News Corporation y también participa Disney.

Figura 4. Netflix

\begin{tabular}{|l|l|l|l|}
\hline \multicolumn{1}{|c|}{ Extiende } & \multicolumn{1}{c|}{ Revierte } & \multicolumn{1}{c|}{ Recupera } & \multicolumn{1}{c|}{ Caduca-disminuye } \\
\hline $\begin{array}{l}\text { Amplía los } \\
\text { contenidos de la } \\
\text { televisión. }\end{array}$ & $\begin{array}{l}\text { Saturación al multiplicarse } \\
\text { las posibilidades de } \\
\text { entretenimiento. }\end{array}$ & $\begin{array}{l}\text { Recupera la } \\
\text { producción de } \\
\text { grandes series de TV. }\end{array}$ & $\begin{array}{l}\text { Hace obsoleta las } \\
\text { series y películas en } \\
\text { discos DVD o Blu-ray. }\end{array}$ \\
\hline
\end{tabular}

Fuente: Elaboración propia

\subsection{IPTV}

La IPTV -en castellano: televisión a través de protocolo de Internet- ha sido desarrollada con base en el video streaming. Se afirma que la televisión actual, en un futuro relativamente próximo, podría evolucionar definitivamente a IPTV. Para ello, sin embargo, resulta indispensable disponer de redes de banda ancha mucho más rápidas, para poder garantizar la deseable calidad en el servicio.

Es importante señalar uno de los aspectos distintivos de la IPTV. A diferencia de los sistemas de televisión abierta, el proveedor no transmite los contenidos esperando que el espectador se conecte. Los contenidos llegan solo cuando el cliente los solicita. Como modalidad de televisión restringida, el usuario paga por el contenido demandado. De acuerdo con Wikipedia, el usuario dispone de un aparato conectado a su ordenador cuya función es agregar una "capa de computación" a su televisor y a través de una guía podrá seleccionar los contenidos que desea ver o acceder a los contenidos que tiene seleccionados desde otras herramientas que usa como Facebook. El aparato conectado dispone de la capacidad necesaria para almacenar contenidos, y de esa manera poder visualizarlos aun cuando está desconectado.

Los contenidos a ofrecer a través de IPTV pueden derivar de los canales tradicionales, como de contenidos más específicos, permitiendo así que los clientes seleccionen aquellos que son de su preferencia, sin importar quién produce los contenidos. Ello, sin duda, favorece el desarrollo de campañas publicitarias de gran precisión, pues los anuncios se pueden dirigir efectivamente a los destinatarios idóneos, y su efectividad también puede ser medida en tiempo real. Por supuesto, el usuario puede bloquear determinados contenidos, por ejemplo, aquellos que considere inapropiados para los niños y menores de edad. De igual modo, el cliente puede solicitar aquellos contenidos que efectivamente se ajusten a demandas temáticas muy específicas.

Figura 5. IPTV

\begin{tabular}{|c|c|c|c|}
\hline Extiende & Revierte & Recupera & Caduca-disminuye \\
\hline $\begin{array}{l}\text { Amplía los } \\
\text { contenidos de la } \\
\text { televisión. }\end{array}$ & $\begin{array}{l}\text { Saturación al } \\
\text { multiplicarse las } \\
\text { posibilidades de } \\
\text { entretenimiento. }\end{array}$ & $\begin{array}{l}\text { Recupera la } \\
\text { posibilidad de } \\
\text { personalizar el } \\
\text { consumo televisivo. }\end{array}$ & $\begin{array}{l}\text { Hace obsoleta las series y } \\
\text { películas de la televisión } \\
\text { abierta, así como en } \\
\text { discos DVD o Blu-ray. }\end{array}$ \\
\hline
\end{tabular}




\section{CONCLUSIÓN}

Efectivamente, hubouna "Edaddela Televisión" y no fue hace mucho tiempo. Durante la segunda mitad del siglo XX, la televisión fue el medio de comunicación masiva que, en buena medida, definió las posibilidades del tiempo libre en la mayoría de las sociedades modernas. En años recientes, con el advenimiento de Internet, las audiencias - principalmente los más jóvenes- paulatinamente fueron relegando a la televisión a un segundo plano. Internet es una plataforma híbrida, resultante del desarrollo de las telecomunicaciones y la computación. La red extiende la mente, convirtiendo al planeta en una aldea global efectivamente interconectada. Internet permite compartir información de forma sincrónica y asincrónica, incluyendo textos, imágenes, audio y video. Internet reubicó a los media que le precedieron. La televisión fue uno de ellos. En la nueva ecología cultural impuesta por Internet, la televisión sencillamente tendrá que adaptarse a nuevos usos culturales. Repensar la televisión a partir de la Tétrada de McLuhan, permite confirmarlo.

Marshall McLuhan inauguró formalmente el estudio de los medios de comunicación electrónicos, anticipando, además, el estudio de los medios digitales, cuyo desarrollo no presenció, pues falleció el 31 de diciembre de 1980 en Toronto, Canadá:

no pudo presenciar la comercialización masiva del ordenador, en la cual el microprocesador, el chip de silicona, Bill Gates, Apple, Netscape y el módem inauguraron la era del PC, Internet, la Red y la realidad virtual. Tampoco pudo implicarse en los correspondientes debates de lo ciberpunk, lo posthumano, la teoría ciborg y la proliferación de cursos académicos sobre medios digitales (Horrocks, 2000, pp. 22-23).

En años recientes, la industria televisiva ha registrado cuantiosas pérdidas. La inversión publicitaria ha disminuido considerablemente, y en buena medida ello se debe a que esta ha sido transferida a Internet, pues a Internet han migrado las audiencias - principalmente los jóvenes-. En el Reino Unido, la inversión publicitaria en Internet supera a la inversión publicitaria en televisión. En Estados Unidos, están a la par. Sin embargo, resulta factible suponer que en los próximos años se incrementará la inversión publicitaria en Internet.

En años recientes, la narrativa de cierto tipo de televisión ha registrado una incuestionable evolución. La teleserie Lost es perfecto ejemplo de ello. La exitosa producción —concebida originalmente para televisión- propició el desarrollo de un amplio número de plataformas cross media. La intersección entre Internet y televisión, definitivamente, no se agota en la televisión extendida. Una de las causas de ruptura más comunes en cualquier sistema "es la fertilización cruzada con otro sistema" (McLuhan, 1996, p. 59). Ello ha ocurrido precisamente con la televisión. Internet la ha transformado. El futuro de la televisión, sin embargo, dependerá de la interactividad. 


\section{REFERENCIAS}

Bolter, J., y Grusin, R. (1999) Remediation. Understanding New Media, USA, The MIT Press.

Casey, Man Kong Lum (Primavera de 2000) "The Intellectual Roots of Media Ecology". En The New Jersey Journal of Communication. Vol. 8. Número 1, pp.1-8.

Costa, J. (2009) Imagen corporativa en el siglo XXI. Buenos Aires: La Crujía.

Crosby, H., and Bond, G. (Editors) (1968) The McLuhan Explosion. New York: American Book Company.

Coupland, D. (2009) Marshall McLuhan. Canadá: Extraordinary Canadians.

Czitrom, D. (1985) De Morse a McLuhan. México: Publigraphics.

Day, B. (1967) The Message of Marshall McLuhan. London: Lintas.

De Kerckhove, D. (1997) Inteligencias en conexión. Hacia una sociedad de la web. Barcelona: Gedisa.

De Kerckhove, D. (1999) La piel de la cultura. Investigando la nueva realidad electrónica. Barcelona: Gedisa.

DeMott, B. “Against McLuhan”. En Stearn, G. (ed). (1967) Hot and Cool A Critical Symposium. New York: The Dial Press.

Duffy, D. (1969) Marshall McLuhan. Toronto: McClelland and Stewart.

Federman M, De Kerckhove, D. (2003) McLuhan for managers. Canadá: Viking.

Fernández, C., y Hernández, R. (2004) Marshall McLuhan, de la torre de control a la torre de marfil. México: Instituto Politécnico Nacional. Disponible en: http://www.razonypalabra.org.mx/ MarshallMcLuhan_DeLaTorreDeMarfilALaTorreDeControl.PDF

Finkelstein, W. (1968) Sense and Nonsense of McLuhan. New York: International Publishers.

Fitzgerald, J. (2001) Marshall McLuhan: wize guy. Montreal: XYZ Publishing.

Goody, J. (1977) The Domestication of the Savage Mind. Cambridge, England and New York: Cambridge University Press.

Gordon, W.T. (1988) Marshall McLuhan. Escape into Understanding: the Authorized Biography. USA: Basic Books.

Gordon, T. (1997) McLuhan for begginers. Nueva York: Writers and readers.

Gordon, W.T (2003) Understanding media: the extension of man. Critical edition. Germany: Ginko Press.

Gordon, W.T. (2010) McLuhan. USA: Continuum. 
Gordon, W.T. (2010) McLuhan. A Guide for the Perplexed. USA: Continuum.

Gordon, W.T, y Willmarth, S. (1988) McLuhan para principiantes. Argentina, Era Naciente NRL.

Gordon, T. (Ed.). (2003) Marshall McLuhan Understanding media. The extensions of man. Critical Edition. Canadá: Ginko Press.

Harrocks, C. (2004) McLuhan y la realidad virtual. España: Gedisa.

Harnecker, M. (2007) Los conceptos elementales del materialismo histórico. México: Siglo XXI.

Innis, H. (1952) Changing Concepts of Time. Toronto: University of Toronto Press.

Innis, Harold. (1999) The bias of communication. Toronto: University of Toronto Press,

Innis, H. (2007) Empire and communications. Canadá: Dundurn Press.

Jenkins, H. (2008) Convergence Culture. La cultura de la convergencia de los medios de comunicación. España: Paidós.

Johnson, S. (1997) Interface culture: How new technology transforms the way we create and communicate. New York: Harper Collins.

Johnson, E; Wolfe, T. (1973) The New Journalism. New York: Harper \& Row.

Kong, C. (2006) Perspectives on culture, technology and communication. USA: Hampton Press.

Kroker, A. (1985) Technology and the Canadian Mind: Innis/McLuhan/Grant. New York, St. Martin's.

Lessig, L. (2006) CODE Version 2.0 New York: Basic Books.

Logan, R. (2004) The alphabet effect. A Media Ecology understanding of the making of Western Civilization. USA: Hampton Press.

Logan, R. (2010) Understanding new media: Extending Marshall McLuhan. New York: Peter Lang.

Logan, R. (2013) McLuhan misunderstood. Setting the record straight. Toronto: Key Publishing House.

Marchand P. (1989) Marshall McLuhan: The medium and the messanger. Toronto: Random House.

Marques de Melo, J. (2007) Entre el saber y el poder. Pensamiento comunicacional latinoamericano. México: UNESCO.

Mattelart, A. (1998) La mundialización de la comunicación. Barcelona: Paidós

Mattelart, A. (2001) Historia de la sociedad de la información. Barcelona: Paidós.

Mattelart, A. (2002) Historia de la utopía planetaria. De la ciudad profética a la sociedad global. Barcelona: Paidós. 
McLuhan E., McLuhan M. (2011) Theories of communication. New York. Peter Lang.

McLuhan, M. (1962) The Gutenberg Galaxy: The making of typographic man. Canadá: Toronto Press.

McLuhan, M. (1969) Counterblast. Toronto: McClelland and Stewart.

McLuhan, M. (1970) Culture is our Business. New York: McGraw-Hill.

McLuhan M. (1996) Comprender los medios de comunicación. Las extensiones del ser humano. Barcelona: Paidos.

McLuhan, M. (1999) The medium and the light. Reflections on religion. Toronto: Stodart.

McLuhan M. (2002) The mechanichal bridge: Folcklore of the Industrial Man.

McLuhan, M. (2005) Marshall McLuhan Unbound. California, Gingko Press.

McLuhan, M., y Carson, D. (2003) The book of probes. New York: Ginko Press.

McLuhan, M y Carpenter, E. (1970) Explorations in Communications. London: Cape.

McLuhan, M y Fiore, Q. (1967) The medium is the message. An inventory of effects. New York: Bantam Books

McLuhan, My Fiore, Q. (1968) War and peace in the global village. New York: Bantam Books.

McLuhan, M., y McLuhan, E. (1988) Laws of media. The new science. Toronto: University of Toronto Press.

McLuhan, M., y McLuhan, E. (2011) Media and formal cause. Texas: NeoPoiesis Press.

McLuhan M., y McLuhan, E., y Hutchcon, K. (1977) The City As Classroom. Ontario: Book Society

McLuhan M., y Nevitt, B. (1972) Take Today: The Executive As Dropout. New York: Harcourt Brace.

McLuhan, M., y Parker, H. (1968) Through the Vanishing Point: Space in Poetry and Painting. New York: Harper.

McLuhan, M., y Powers, B. (1989) The global village, Transformations in world life and media in the 21st Century. New York: Oxford University Press.

McLuhan, M., y Watson, W. (2011) From Cliche to archetype. Canadá: Ginko Press.

McLuhan, S., Staines, D (Eds.). (2003) Marshall McLuhan. Understanding me. Lectures and interviews. Toronto: M\&S.

Miller, J. (1973) McLuhan. Barcelona: Grijalbo. 
Molinaro, M., McLuhan, C., Toye, W. (Eds.). (1987) Letters of Marshall McLuhan. Toronto: Oxford University Press.

Morrison, J. (2000) "Hypermedia and synesthesia". Proceedings of the Media Ecology Association, Inaugural Convention, Fordham University, New York, N. Y., June 16-17.

Mumford, L. (1961) La ciudad en la historia: sus orígenes, transformaciones y perspectivas. Buenos Aires: Infinito.

Pavlik, J. (1998) New Media Technology. Cultural and commercial perspectives. MA: Allyn \& Bacon.

Postman, N. (1986) Amusing ourselves to death: Public discourse in the age of show business. New York: Penguin.

Postman, N. (1992) Technopoly: The surrender of culture to technology. New York: Knopf.

Postman, N., y Weingartner, C. (1969) Teaching as a Subversive Activity. New York: Delacorte.

Rosenthal, R. (ed). (1968) McLuhan: Pro and Con. USA: Funk and Wagnalls.

Rushkoff, D. (2006) Screenagers. Lessons in chaos from digital kids. New York: Hampton Press.

Sanderson, G., y McDonald, F. (1989) The unknown McLuhan. Colorado: Fulcrum.

Sanderson, F., y Mcdonald, F. (1989) Marshall McLuhan: The Man and His Message. Colorado: Fulcrum.

Scolari, C. (2008) Hipermediaciones. Elementos para hacer una teoría de la comunicación digital interactiva. Barcelona: Gedisa.

Steam, G. (1967) McLuhan: hot \& cool. Nueva York: The Dial Press.

Strate, L. (2014) Amazing ourselves to death. Neil Postman's brave new world revisted. New York: Peter Land.

Strate, L., Jacobson, R \& Gibson, S. (2003) (Eds.). Communication and Cyberspace. Social Interaction in an electronic environment. USA: Hampton Press.

Surowiecki, J. (2004) The wisdom of crowds. New York: Anchor Books.

Theall, D. (1971) Understanding McLuhan. The medium is the rear view mirror. Montreal: McGillQueen’s University Press.

Theall, D. (2001) The virtual Marshall McLuhan. Montreal: McGill-Queen’s University Press. Toffler, A. (1981) La tercera ola. México: Edivisión. 